\title{
THE LIGHT CHAIN OF TETANUS TOXIN INHIBITS CALCIUM-DEPENDENT VASOPRESSIN RELEASE FROM PERMEABILIZED NERVE ENDINGS
}

\author{
G. Dayanithi, ${ }^{*} \dagger \ddagger$ U. Weller,,$\S \|$ G. AhNert-Hilger, ${ }^{*} \|$ H. Link,,${ }^{*}$ J. J. NordmanN $₫$ \\ and M. GRATZL* \\ *Abteilung Anatomie und Zellbiologie der Universität Ulm, D-7900 Ulm, F.R.G. \\ $\S$ Institut für Medizinische Mikrobiologie der J. Gutenberg-Universität, D-6500 Mainz, F.R.G. \\ ףCentre de Neurochimie du CNRS, F-67084 Strasbourg, France
}

\begin{abstract}
The effects of tetanus toxin and its light and heavy chain subunits on vasopressin release were investigated in digitonin-permeabilized neurosecretory nerve terminals isolated from the neural lobe of the rat pituitary gland. Exocytosis was induced by challenging the permeabilized nerve endings with micromolar calcium concentrations. Tetanus toxin inhibited vasopressin release only in the presence of the reducing agent dithiothreitol. This effect was irreversible. The purified light chain of tetanus toxin strongly inhibited exocytosis in a dose-dependent manner with half-maximal effect at $c .10 \mathrm{nM}$. The action of the light chain was observed after only $2.5 \mathrm{~min}$ of preincubation. Separated heavy chain subunit had no effect on hormone secretion. Inhibition of vasopressin release could be prevented by preincubating the light chain of tetanus toxin with an immune serum against tetanus toxin.

The data clearly demonstrate that in mammalian neurosecretory nerve endings tetanus toxin acts at a step downstream from the activation by $\mathrm{Ca}^{2+}$ of the exocytotic machinery and that the functional domain of this toxin is confined to its light chain.
\end{abstract}

In recent years, increasing use has been made of bacterial, plant and animal toxins in neurobiological research. A potent bacterial neurotoxin synthesized as a single-chain protein by Clostridium tetani is tetanus toxin (for reviews see Refs 13, 24). Subsequent proteolytic processing leads to a pharmacologically more active molecule ${ }^{27}$ which consists of disulfide-linked heavy $(100,000 \mathrm{~mol}$. wt) and light $(50,000 \mathrm{~mol}$. wt) chains. Tetanus toxin is a potent inhibitor of neurotransmitter secretion from neuronal tissue. For example, neurotransmitter release at central inhibitory synapses, ${ }^{17}$ at neuromuscular junctions $^{18}$ or at nerve endings of the neurohypophysis ${ }^{14}$ is strongly reduced in the presence of the toxin. It has been shown that the individual chains of tetanus toxin alone are not neurotoxic in vivo. ${ }^{16}$ Application of tetanus toxin to intact cells in culture or intoxication in vivo requires hours before transmitter release is blocked. This delay reflects the time required for the binding of the toxin to the plasma membrane followed by internalization and intracellular action (cf. Ref. 13). In vertebrates the domain binding to the cell surface appears to be localized at the C-terminal of the heavy chain (cf. Ref. 24).

†Present address: Centre de Neurochimie du CNRS, 5 rue Blaise Pascal, F-67084 Strasbourg, France.

$\ddagger$ To whom correspondence should be addressed.

॥Present address: Abteilung für Neuropsychopharmakologie der Freien Universität, 1000 Berlin, F.R.G.

Abbreviations: AVP, arginine vasopressin; DTT, dithiothreitol; EGTA, ethyleneglycolbis ( $\beta$-aminoethylether) $N, N^{\prime}$ tetra-acetate; HEPES, $N$-2-hydroxyethylpiperazine- $N^{\prime}$ 2-ethanesulfonic acid; PIPES, piperazine- $N$ - $N^{\prime}$-bis(2ethanesulfonic acid).
Extracellular application of tetanus toxin does not allow the differentiation of the intracellular processes involved in the final inhibition of neurotransmitter release and the role played by the individual chains of the toxin. When directly injected into adrenal medullary chromaffin cells, tetanus toxin inhibits exocytosis. ${ }^{22}$ Also, in permeabilized chromaffin cells, tetanus toxin turned out to be a potent inhibitor of catecholamine secretion. ${ }^{1.7}$ In addition it has been shown that the light chain alone is capable of blocking exocytosis when introduced directly into cultured adrenal chromaffin cells. ${ }^{2,6}$

Recently, using permeabilized adrenal chromaffin cells or isolated mammalian neurosecretory nerve terminals, it has been demonstrated that intracellular application of the closely related neurotoxin botulinum $A$ toxin is more effective in the presence of a reducing agent. ${ }^{10,25}$ Furthermore it has been found that the light chain of botulinum $\mathrm{A}$ toxin alone inhibits $\mathrm{Ca}^{2+}$-stimulated catecholamine secretion ${ }^{5,26}$ and vasopressin release from nerve terminals. ${ }^{10}$ In the present study mammalian permeabilized neurosecretory nerve terminals were used to address the intra-terminal effect of tetanus toxin on neurohypophysial hormone release.

\section{EXPERIMENTAL PROCEDURES}

Male Wistar rats (Charles River, Sulzfeld, F.R.G.) of $250-300 \mathrm{~g}$ body weight were decapitated and the neural lobe was washed with normal Locke saline containing (in $\mathrm{mM}$ ): $\mathrm{NaCl}, 140 ; \mathrm{KHCO}_{3}, 5 ; \mathrm{MgCl}_{2}, 1 ; \mathrm{CaCl}_{2}, 2.2$; Tris-HEPES, 10; glucose, 10; bovine serum albumin (Miles Laboratories, U.S.A.), $0.025 \%$, pH 7.25. The medium was then replaced with a buffer containing $270 \mathrm{mM}$ sucrose, $10 \mathrm{mM}$ Tris- 
HEPES, and $2 \mathrm{mM}$ EGTA. The nerve endings were then isolated as described by Cazalis et $a l^{9}$ Briefly, the neurohypophyses were homogenized in the buffered sucrose solution and centrifuged at $100 \mathrm{~g}$ for $1 \mathrm{~min}$. The supernatant was taken and centrifuged further at $2400 \mathrm{~g}$ for $5 \mathrm{~min}$. The pellet contains mostly isolated nerve endings as judged by electron microscopy, ${ }^{20}$ Throughout the isolation procedure and the experiment the temperature was maintained at $37^{\circ} \mathrm{C}$. The nerve endings were then resuspended in normal Locke solution and loaded onto $0.2-\mu \mathrm{m}$ Gelman filters (Acro, LC 13).

The isolated nerve endings were perifused by means of a multichannel peristaltic pump (Ismatec IPN 8) for $60 \mathrm{~min}$ with normal Locke at a flow rate of $50 \mu 1 / \mathrm{min}$ which was then increased to $100 \mu \mathrm{l} / \mathrm{min}$ until the end of the experiment The perifusion was further continued with normal Locke containing no $\mathrm{Ca}^{2+}$ but $5 \mathrm{mM}$ EGTA for $10 \mathrm{~min}$. The medium was then replaced by $\mathrm{K}^{+}$-glutamate buffer (medium B) containing (in $\mathrm{mM}$ ): $\mathbf{K}^{+}$-glutamate, 130; $\mathrm{MgCl}_{2}, 2$; EGTA, 5; glucose, 10 ; piperazine- $N-N^{\prime}-\mathrm{bis} / 2-$ ethanesulfonic acid (PIPES), 20; bovine serum albumin, $0.025 \%, \mathrm{pH} 6.8$, and the perifusion run for a further $30 \mathrm{~min}$. For permeabilization, the nerve endings were perifused for 5 min with $I \mu \mathrm{M}$ digitonin in medium $\mathbf{B}$. Subsequently, the terminals were perifused for $25 \mathrm{~min}$ with the various forms of tetanus toxin dissolved in medium B supplemented with $1 \mathrm{mM}$ dithiothreitol (DTT). Stimulation was performed for 10 min with medium B supplemented with $10 \mu \mathrm{M}$ free $\mathrm{Ca}^{2+}$. Collection of the perfusate by means of a fraction collector (Gilson-203) started $130 \mathrm{~min}$ after loading, i.e. 6 min before the $\mathrm{Ca}^{2}+$ stimulation. Fractions were collected every $2 \mathrm{~min}$ and immediately frozen until radioimmunoassay for released arginine vasopressin (AVP) was performed. ${ }^{\text {. The }}$ $\mathrm{Ca}^{2+}$-evoked hormone release was calculated by subtracting the mean basal release determined in the fractions preceding the onset of the $\mathrm{Ca}^{2+}$ stimulus from the amount of hormone found in each of the following eight fractions. ${ }^{9}$ Free $\mathrm{Ca}^{2+}$ concentrations were calculated and controlled with a $\mathrm{Ca}^{2+}$ sensitive electrode. ${ }^{3.12}$

Tetanus toxin was separated into its heavy and light chains by isoelectric focusing in a sucrose gradient with ampholyte under reducing conditions in $2 \mathrm{~mol} / 1$ urea ${ }^{27,28}$ The isoelectric points were $5.9,4.8$, and 7.2 for tetanus toxin, its light and heavy chain, respectively. Toxicity (LD ${ }_{50}, \mathrm{~s}, \mathrm{c}$. in mice) was $2 \mathrm{ng} / \mathrm{kg}$ for the toxin $100-300 \mu \mathrm{g} / \mathrm{kg}$ for the heavy chain and $30-40 \mu \mathrm{g} / \mathrm{kg}$ for the light chain. Before use, all toxin preparations were dialysed against medium $\mathrm{B}$.

Tetanus toxin-antiserum, an immune serum from horse $(5000 \mathrm{IU} / \mathrm{ml})$, was obtained from Behring Werke, Marburg. F.R.G., and dialysed against medium B before use.

\section{RESULTS}

A typical secretory response of digitonin-permeabilized nerve endings challenged with $\mathrm{Ca}^{2+}$ following incubation with tetanus toxin (two-chain form) in the presence or the absence of a reducing agent DTT is shown in Fig. 1. In the presence of DTT, inhibition of the $\mathrm{Ca}^{2+}$-induced AVP release was observed after incubation of the permeabilized nerve endings with the toxin during a period of $25 \mathrm{~min}$. In contrast, in the absence of the reducing agent, tetanus toxin had no effect on the magnitude and the time-course of the secretory response. Inhibition of evoked AVP release was observed at a concentration as low as $5 \mathrm{nM}$ but this inhibitory effect was only observed in the presence of DTT.

The effect of tetanus toxin on AVP release during two successive stimulations with $10 \mu \mathrm{M}$ free $\mathrm{Ca}^{2+}$ is

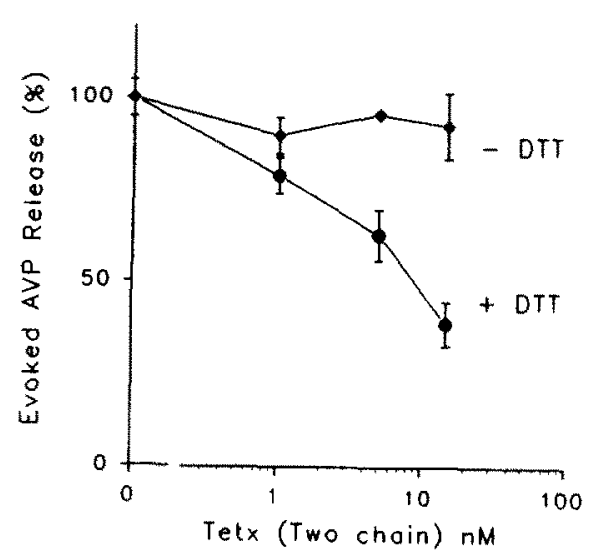

Fig. 1. Tetanus toxin inhibits $\mathrm{Ca}^{2+}$-induced AVP release from permeabilized nerve terminals in the presence of DTT. Following permeabilization, the nerve endings were incubated for $25 \mathrm{~min}$ at $37^{\circ} \mathrm{C}$ with various amounts of tetanus toxin (Tetx) with or without DTT (1 $\mathrm{mM}$ ). AVP release was triggered by challenging the nerve endings with $10 \mu \mathrm{M}$ free $\mathrm{Ca}^{2+}$. Each value represents the mean \pm S.E.M. of three experiments except that at $5 \mathrm{nM}$ tetanus toxin in the absence of DTT for which the two values (closed circles) are indicated. The release caused by $15 \mathrm{nM}$ tetanus toxin in the presence of DTT differs significantly $(P<0.01)$ from that in the absence of DTT.

shown in Fig. 2. When, following a first $\mathrm{Ca}^{2+}$ challenge, the nerve endings from control experiments were exposed to a second $\mathrm{Ca}^{2+}$ challenge, $34 \mathrm{~min}$ later they showed a robust secretory response. However, when permeabilized nerve endings were incubated for a period of $25 \mathrm{~min}$ with $50 \mathrm{nM}$ tetanus toxin in the presence of DTT, significant inhibition of $\mathrm{Ca}^{2+}$-stimulated release was already observed during the first $\mathrm{Ca}^{2+}$ challenge. When compared to the control experiment the toxin-treated nerve endings were then challenged with a second $\mathrm{Ca}^{2+}$ pulse, they showed no recovery of the secretory response after the $34 \mathrm{~min}$ washout period in the absence of the toxin. Thus, the effect of the toxin is irreversible.

In order to determine the minimum time required for the toxin to exert an inhibitory effect on AVP release, permeabilized nerve terminals were incubated in the presence of the toxin $(79 \mathrm{nM})$ for different periods of time. We found that a treatment of only $2.5 \mathrm{~min}$ with the toxin was sufficient to give an inhibition of exocytosis by $44.2 \%$ while after $25 \mathrm{~min}$ an inhibition by $55.6 \%$ occurred.

The dose dependence of the inhibition of secretion by the light chain of tetanus toxin is illustrated in Fig. 3. $I_{50}$ was observed at a concentration of c. $10 \mathrm{nM}$. Note that high concentrations of the toxin did not completely abolish the $\mathrm{Ca}^{2+}$-induced AVP release. The inhibitory effect of tetanus toxin light chain on stimulated AVP secretion was fully overcome by preincubating, before its addition to the nerve endings preparation, the light chain with an immune serum against tetanus toxin. The results are shown in Fig. 4. They demonstrate the specificity of the toxin on the secretory process. 


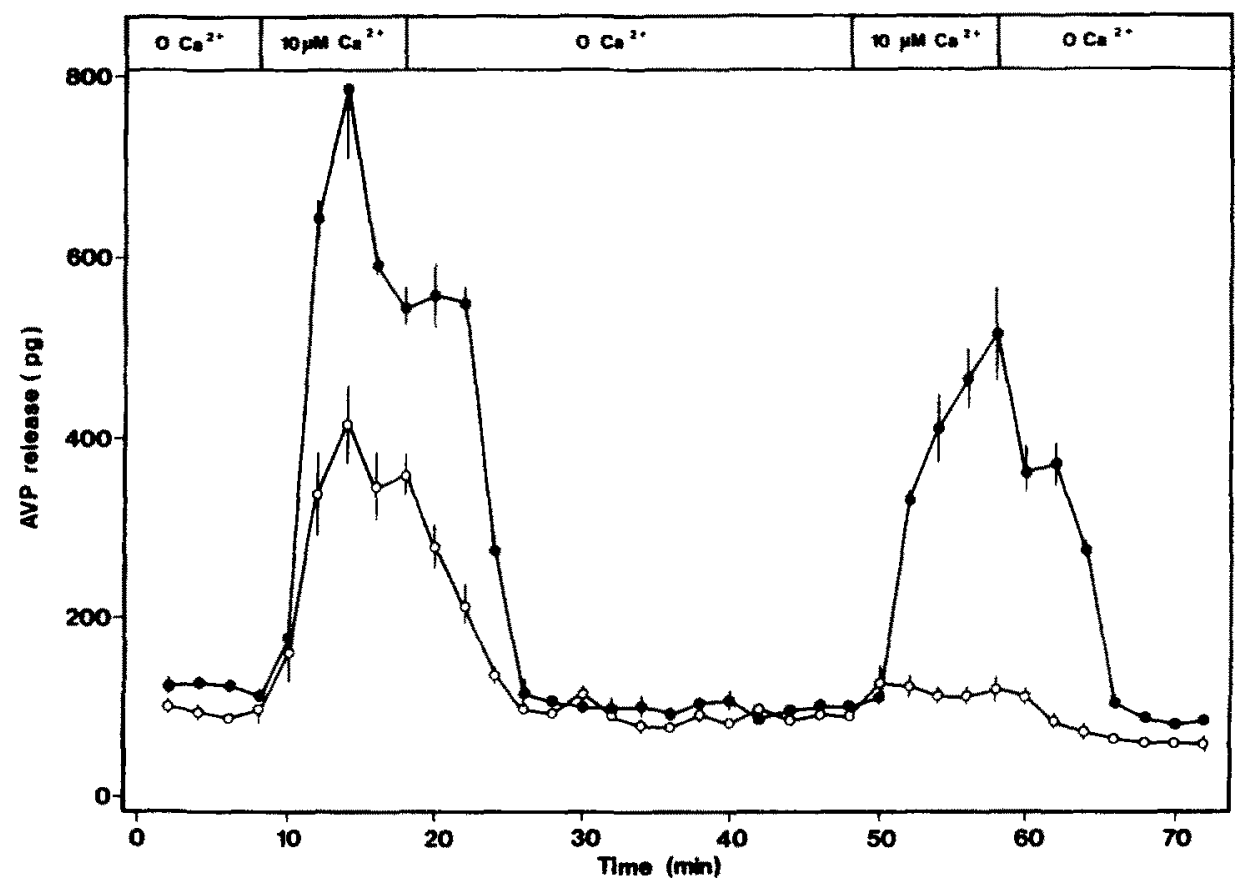

Fig. 2. Effect of tetanus toxin on AVP release from permeabilized nerve terminals during two successive challenges with $\mathrm{Ca}^{2+}$. The isolated nerve endings were perfused with buffer (medium B). After permeabilization they were preincubated for $25 \mathrm{~min}$ with or without $50 \mathrm{nM}$ tetanus toxin in the presence of DTT ( $1 \mathrm{mM}$ ) which was also present in control experiments. The nerve endings were then challenged with $10 \mu \mathrm{M}$ free $\mathrm{Ca}^{2+}$ for $10 \mathrm{~min}$. After a washout period of $35 \mathrm{~min}$ in the absence of free $\mathrm{Ca}^{2+}$ the nerve endings were challenged again with $10 \mu \mathrm{M}$ free $\mathrm{Ca}^{2+}$ for $10 \mathrm{~min}$. Vasopressin release was measured in each fraction ( $2 \mathrm{~min}$ ). The open circles represent AVP secretion from tetanus toxin-treated nerve terminals and the closed circles represent that from control experiments. Values are expressed as mean \pm S.E.M. $(n=4)$.

In order to find out whether the light chain of tetanus toxin alone is responsible for the observed effects or whether the heavy chain modifies the action of the light chain, equimolar $(10 \mathrm{nM})$ concentrations

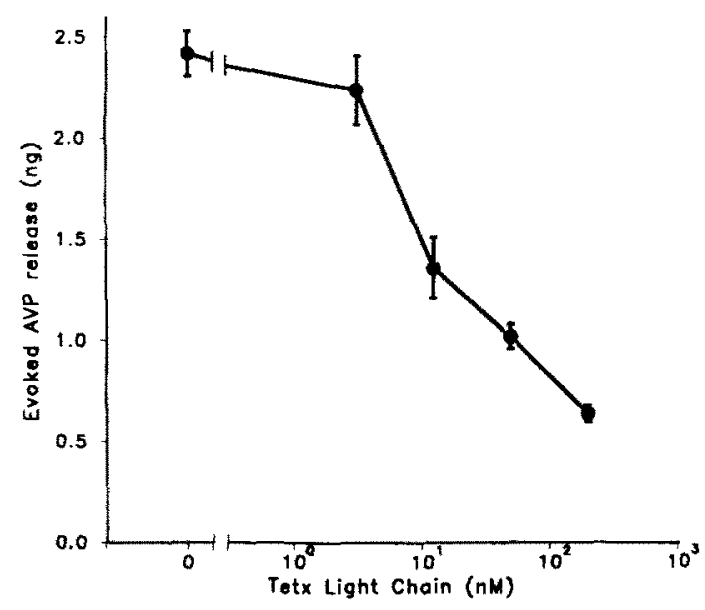

Fig. 3. Dose-response curve of the inhibitory effect of tetanus toxin light chain on $\mathrm{Ca}^{2+}$-stimulated vasopressin release from permeabilized nerve terminals. Permeabilized nerve endings were preincubated for $25 \mathrm{~min}$ with increasing amounts of tetanus toxin (Tetx) light chain (abscissa). The experimental details are the same as in Fig. $2 . \mathrm{Ca}^{2+}$ evoked AVP release is expressed as nanograms. The values are expressed as the mean of three to five experiments \pm S.E.M. of heavy and light chains were applied simultaneously as well as separately. In contrast to the light chain, the heavy chain itself had no effect on AVP release (Fig. 4). Furthermore, the heavy chain did not modify the effect of the light chain on hormone secretion.

\section{DISCUSSION}

Tetanus toxin and botulinum toxins are extremely potent neurotoxins produced by the anaerobic bacteria of the Clostridium genus. In several in vitro studies it has been demonstrated that tetanus toxin blocks the release of both inhibitory and excitatory neurotransmitters from a number of neuronal cell types. However, the effects of tetanus toxin and the separated chains on neurohormone release are still not known. Isolated neurosecretory nerve terminals from the posterior pituitary are an ideal preparation to study the action of neurotoxins, because they can be permeabilized and the intra-terminal regulation of exocytosis can be analysed. ${ }^{9,21}$ Using the above model, we present the first report on intracellular action of tetanus toxin in a mammalian neuron.

The results reported here indicate that the twochain form of tetanus toxin inhibits more effectively the $\mathrm{Ca}^{2+}$-stimulated AVP release in the presence of a reducing agent, suggesting that the disulfide bridge which links the heavy and the light chain of the toxin 


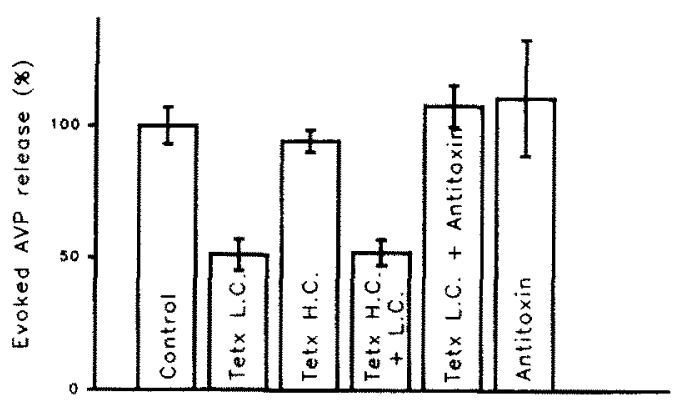

Fig. 4. Specificity of the effect of tetanus toxin (Tetx) light chain on $\mathrm{Ca}^{2+}$-evoked vasopressin release from permeabilized nerve terminals. The experimental procedure was the same as in Fig. 2. The permeabilized nerve terminals were either preincubated with buffer (control), or with $10 \mathrm{nM}$ heavy (H.C.) and light chain (L.C.), alone or after previous combination. The effect of $9.2 \mathrm{IE} / \mathrm{ml}$ antitoxin to tetanus toxin light chain, an immune serum from horse with or without light chain was also investigated. Evoked AVP release (percentage of control) with $10 \mu \mathrm{M}$ free $\mathrm{Ca}^{2+}$ within $10 \mathrm{~min}$ was expressed as mean of four experiments \pm S.E.M. Note that the heavy chain has no inhibitory effect on hormone secretion and does not interfere with the action of its light chain. The release was significantly $(P<0.01)$ inhibited by tetanus toxin light chain and tetanus toxin heavy chain plus light chain.

has to be cleaved before exocytosis can be inhibited. Our recent results, obtained with the closely related botulinum $\mathrm{A}$ toxin in permeabilized nerve endings, ${ }^{10}$ are along this line. Similarly, in chromaffin cells the single-chain form of tetanus toxin in which the light and the heavy chain are linked by peptide bonds is ineffective, the potency of the two-chain form is increased by a reducing agent and the light chain alone is fully inhibitory. ${ }^{1.2}$

Other lines of evidence from this report indicate that the action of tetanus toxin was irreversible and removal of toxin does not restore exocytosis. More interestingly and of importance for further neurobiological investigations, the action of tetanus toxin on AVP secretion in permeabilized nerve endings is very rapid (within $2.5 \mathrm{~min}$ ). Furthermore, increasing the preincubation period prior to $\mathrm{Ca}^{2+}$ stimulation did not increase the degree of inhibition, a fact which is in accordance with an earlier report on permeabilized chromaffin cells. 'We suggest, therefore, that the minimum time requirement for the action of botulinum $\mathrm{A}$ toxin on other tissues and tetanus toxin on neurohypophysial hormone release is quite different, and tetanus toxin action is more rapid than botulinum $\mathrm{A}$ toxin in the same system.

Once in a cytosolic compartment the heavy chain, which may be necessary for internalization, is no longer required for full activity of the light chain. In contrast to the light chain, the heavy chain itself has no effect on vasopressin release. Furthermore, the heavy chain did not modify the effect of the light chain on hormone secretion.

The latter observation is in contrast with results obtained with botulinum A toxin, in which the heavy chain reduces the inhibitory effect of the light chain. ${ }^{10}$ Thus the properties of vasopressin secretion observed here are very similar to catecholamine release. In both systems the light chain alone is effective and its action is unaffected by the added heavy chain in the case of tetanus toxin, while inhibition by the light chain of botulinum $A$ toxin is abolished by the added heavy chain. ${ }^{2.26}$ In Aplysia cholinergic neurons, the situation is completely different; namely, both heavy and light chains are necessary to manifest the toxic effect of botulinum $\mathrm{A}$ toxin. ${ }^{15,23}$ On the other hand, only the light chain of tetanus toxin is required for inhibiting transmitter release in Aplysia neurons and this process is not modified by intracellular application of the heavy chain. ${ }^{19}$ The reason for the differences in the action of botulinum $A$ toxin and tetanus toxin in mammalian and invertebrate systems is not known at present. Both differences in the sequences of botulinum $A$ and tetanus toxin ${ }^{4.11}$ and differences in the mechanism of release of neuropeptides from mammalian nerve terminals compared to that of synaptic vesicles from Aplysia neurons must be taken into consideration.

\section{CONCLUSION}

The present data show that the light chain of tetanus toxin is responsible for a strong inhibitory effect of neurohormone secretion from mammalian nerve endings. Also, it can be concluded that the toxin acts at a step downstream from the activation by $\mathrm{Ca}^{2+}$ of the exocytotic machinery. The data support previous investigations carried out with chromaffin cells ${ }^{1,2,6}$ and extend them to nerve endings, i.e. structures directly involved in tetanus toxin-induced disease.

Acknowledgements - We would like to thank Dr John Bicknell (Babraham, U.K.) for AVP antiserum and Dr K. D. Hungerer from the Behring Werke AG (Marburg, F.R.G.) for the supply of Clostridium tetani culture filtrate. G. Dayanithi is a fellow of Alexander von Humboldt Foundation, F.R.G. This work was supported by the Deutsche Forschungsgemeinschaft (Gr 681 and SFB 249) and grants from CNRS and INSERM. We are indebted to Mrs B. Mader for typing this manuscript and to $\mathrm{Mr}$ W. Podschuweit for preparing the figures.

\section{REFERENCES}

1.' Ahnert-Hilger G., Bader M. F., Bhakdi S. and Gratzl M. (1989) Introduction of macromolecules into bovine adrenal medullary chromaffin cells and rat pheochromocytoma cells ( $\mathrm{PC1}$ ) by permeabilization with streptolysin $\mathrm{O}$ : inhibitory effect of tetanus toxin on catecholamine secretion. J. Neurochem. 52, 1751-1758.

2. Ahnert-Hilger G., Weller U., Dauzenroth M. E., Habermann E. and Gratzl M. (1989) The tetanus toxin light chain inhibits exocytosis. Fedn Eur, biochem. Socs Lett. 242, 245-248. 
3. Ammann D., Bührer T., Schefer U., Müller M. and Simon W. (1987) Intracellular neutral carrier-based calcium microelectrode with subnanomolar detection limit. Eur. J. Physiol. 409, 223-228.

4. Binz T., Kurazono H., Wille M., Frevert J., Wernars K. and Niemann H. (1990) The complete sequence of botulinum neurotoxin type A and comparison with other clostridial neurotoxins. J. biol. Chem. 265, 9153-9158.

5. Bittner M. A., DasGupta B. R. and Holz R. W. (1989) Isolated light chains of botulinum neurotoxins inhibit exocytosis. J. biol. Chem. 264, 10,354-10,360.

6. Bittner M. A., Habig W. H. and Holz R. W. (1989) Isolated light chain of tetanus toxin inhibits exocytosis: studies in digitonin-permeabilized cells. J. Neurochem. 53, 966-968.

7. Bittner M. A. and Holz R. W. (1988) Effects of tetanus toxin on catecholamine release from intact and digitoninpermeabilized chromaffin cells. J. Neurochem. 51, 451-456.

8. Cazalis M., Dayanithi G. and Nordmann J. J. (1985) The role of patterned burst and interburst interval on the excitation-coupling mechanisms in the isolated rat neural lobe. J. Physiol., Lond. 369, 45-60.

9. Cazalis M., Dayanithi G. and Nordmann J. J. (1987) Hormone release from isolated nerve endings of the rat neurohypophysis. J. Physiol. 390, 55-70.

10. Dayanithi G., Ahnert-Hilger G., Weller U., Nordmann J. J. and Gratzl M. (1990) Release of vasopressin from isolated permeabilized neurosecretory nerve terminals is blocked by the light chain of botulinum A toxin. Neuroscience 39 , $711-715$.

11. Eisel U., Jarausch W., Goretzki K., Henschen A., Engels J., Weller U., Hudel M., Habermann E. and Niemann H. (1986) Tetanus toxin: primary structure expression in E. coli, and homology with botulinum toxins. Eur. molec. Biol. Org. J. 5, 2495-2502.

12. Föhr K. J., Warchol W. and Gratzl M. (1991) Calculation and control of free divalent cations in solutions used for membrane fusion studies. Meth. Enzym. (in press).

13. Habermann E. and Dreyer F. (1986) Clostridial neurotoxins: handling and action at the cellular and molecular level. Curr. Topics Microbiol. Immun. 129, 93-179.

14. Halpern J. L., Habig W. H., Trenchard H. and Russell J. T. (1990) Effect of tetanus toxin on oxytocin and vasopressin release from nerve endings of the neurohypophysis. $J$. Neurochem. 55, 2072-2078.

15. Maisey E. A., Wadsworth D. F., Poulain B., Shone C., Melling J., Gibbs P., Tauc L. and Dolly J. O. (1988) Involvement of the constituent chains of botulinum neurotoxins $\mathrm{A}$ and $\mathrm{B}$ in the blockade of neurotransmitter release. Eur. J. Cell Biol. 177, 683-691.

16. Matsuda M. and Yoneda M. (1976) Reconstitution of tetanus neurotoxin from two antigenically active polypeptide fragments. Biochem. biophys. Res. Commun. 68, 668-674.

17. Mellanby J. (1984) Comparative activities of tetanus and botulinum toxins. Neuroscience 11, 29-34.

18. Mellanby J. and Thompson P. A. (1972) The effect of tetanus toxin at the neuromuscular junction in the goldfish. J. Physiol., Lond. 224, 407-419.

19. Mochida S., Poulain B., Weller U., Habermann E. and Tauc L. (1989) Light chain of tetanus toxin intracellularly inhibits acetylcholine release at neuro-neuronal synapses, and its internalization is mediated by heavy chain. Fedn Eur. biochem. Socs Lett. 253, 47-51.

20. Nordmann J. J. and Dayanithi G. (1988) Release of neuropeptides does not only occur at nerve terminals. Biosci. Rep. $8,471-483$.

21. Nordmann J. J., Dayanithi G. and Lemos J. R. (1987) Isolated neurosecretory nerve endings as a tool for studying the mechanism of stimulus-secretion coupling. Biosci. Rep. 7, 411-426.

22. Penner R., Neher E. and Dreyer F. (1986) Intracellularly injected tetanus toxin inhibits exocytosis in bovine adrenal chromaffin cells. Nature 324, 76-78.

23. Poulain B., Tauc L., Maisey E. A., Wadsworth J. D. F., Mohan P. M. and Dolly J. O. (1988) Neurotransmitter release is blocked intracellularly by botulinum neurotoxin, and this requires uptake of both toxin polypeptides by a process mediated by the larger chain. Proc. natn. Acad. Sci. U.S.A. 85, 4090-4094.

24. Simpson L. L. (1986) Molecular pharmacology of botulinum toxin and tetanus toxin. A. Rev. Pharmac. Toxicol. 26 $427-453$.

25. Stecher B., Gratzl M. and Ahnert-Hilger G. (1989) Reductive chain separation of botulinum A toxin-a prerequisite to its inhibitory action on exocytosis in chromaffin cells. Fedn Eur. biochem. Socs Lett. 248, 23-27.

26. Stecher B., Weller U., Habermann E., Gratzl M. and Ahnert-Hilger G. (1989) The light chain but not the heavy chain of botulinum A toxin inhibits exocytosis from permeabilized adrenal chromaffin cells. Fedn Eur. biochem. Socs Lett. 255, 391-394.

27. Weller U., Mauler F. and Habermann E. (1988) Tetanus toxin: biochemical and pharmacological comparison between its protoxin and some isotoxins obtained by limited proteolysis. Naunyn-Schmiedeberg's Arch. Pharmac. 338, 99-106.

28. Weller U., Dauzenroth M. E., Meyer zu Heringsdorf D. and Habermann E. (1989) Chains and fragments of tetanus toxin: separation, reassociation and pharmacological properties. Eur. J. Biochem. 182, 649-656. 